\title{
SISTEM INFORMASI PERSEDIAAN BARANG PADA PT.HANKOOK CERAMIC INDONESIA
}

\author{
Dedeh Supriyanti ${ }^{1}$ \\ Yudo Bangun Romadhon ${ }^{2}$ \\ Dedy Iskandar ${ }^{3}$
}

E-mail : dedeh@raharja.info, yudo@raharja.info, iskandar@raharja.info

\begin{abstract}
ABSTRAKSI
Di era perkembangan teknologi informasi pada saat ini, pemanfaatan komputer di PT. Hankook Ceramic Indonesia sangatlah penting untuk menunjang kebutuhan- kebutuhan informasi di PT. Hankook Ceramic Indonesia. Penggunaan komputer merupakan hal yang wajib, karena dengan adanya sistem terkomputerisasi segala proses mulai dari pengolahan data hingga dokumen penting lainnya dapat tersusun dengan rapih sehingga dapat mempermudah penyimpanan dan pencarian data. masalah yang dihadapi pada sistem informasi persediaan barang di PT. Hankook Ceramic Indonesia adalah kurang adanya sistem informasi yang akurat, cepat, dan tepat walaupun sistem persediaan barang yang ada pada PT. Hankook Ceramic Indonesia masih menggunakan microsoft office namun masih belum maksimal, sehingga didalam menghasilkan seluruh laporan yang akurat dan tepat relatif lama. Adapun tujuan dari penelitian yang dilakukan penulis adalah melakukan analisa terhadap sistem informasi yang berjalan pada PT. Hankook Ceramic Indonesia. Metodologi yang digunakan yaitu dengan pendekatan siklus hidup pengembangan sistem mulai dari menganalisa sistem yang berjalan melalui UML (Unified Modeling Languange), melakukan elisitasi serta hasil akhir yang dicapai dari laporan yaitu terbentuknya suatu prosedur sistem dengan menggunkan program UML untuk menggambarkan analisa sistem yang berjalan dan analisa sistem yang diusulkan. Selain itu dihasilkan pula perancangan sistem informasi persediaan barang yang diharapkan dapat meningkatkan kinerja operasional pada pegawai PT. Hankook Ceramic Indonesia.
\end{abstract}

Kata Kunci : Sistem informasi, UML, persediaan Barang

\section{PENDAHULUAN}

Perkembangan dalam dunia usaha dapat di tandai dengan semakin banyaknya perusahaanperusahaan yang bergerak dalam bidang industri, perdagangan maupun jasa. Pada dasarnya perusahaan didirikan memiliki tujuan. tujuan utama suatu perusahaan adalah bagaimana agar perusahaan dapat menjaga kelangsungan hidupnya dan menjaga kesinambungan usaha agar tetap bertahan dalam persaingan. Pada sebuah perusahaan instansi besar maupun kecil selalu ada persediaan terutama persediaan barang untuk memproduksi, dengan sistem informasi persediaan barang yang baik berpengaruh sekali bagi perkembangan dan kemajuan suatu perusahaan atau instansi terutama yang bergerak dalam bidang produksi. Sistem informasi persediaan barang yang kurang baik akan berpengaruh terhadap aspek lain, seperti kurangnya kepercayaan konsumen atau pelanggan terhadap perusahaan, PT. Hankook
Ceramic Indonesia merupakan perusahaan yang bergerak dalam bidang produksi piranti makanan, dalam pendataan persediaan barang yang terdapat di PT. Hankook Ceramic Indonesia sudah terkomputerisasi tapi masih menggunakan Microsoft Office, sehingga memungkinkan terjadinya banyak kesalahan yaitu selisih antara persediaan barang yang ada dengan pemakaian barang dan tidak efektif karena memakan waktu yang lama dalam penghitungannya, dengan ini saya mencoba memberikan suatu perancangan sistem informasi persediaan barang yang terkomputerisasi dengan berbasis web

\section{PERMASALAHAN}

1. Bagaimana mengontrol keluar masuk barang?

2. Bagaimana laporan persediaan barang saat ini? 
3. Bagaimana perusahaan dapat mengetahui jumlah persediaan barang secara cepat dan akurat?

4. Dengan adanya sistem yang optimal maka diharapkan laporan perbaikan dapat dibuat dengan tepat, akurat dan cepat.

\section{PEMBAHASAN}

Definisi Konsep Persedian Barang

(Kusumawati,2010:178) pengertian produksi sebagai berikut: "Barang yang di beli/diproduksi/dimiliki perusahaan yang akan di jual kembali sebagai aktivitas atau kegiatan normal perusahaan. " (Waluyo,2011:66) Barang jadi yang telah diproduksi atau barang dalam penyelesaian, termasuk bahan serta perlengkapan yang akan digunakan dalam proses produksi. Berdasarkan beberapa pendapat yang dikemukakan diatas dapat ditarik kesimpulan bahwa "Barang-barang yang dimiliki perusahaan untuk dijual kembali atau memproduksi barangbarang yang akan di jual."

\section{A. Jenis Persediaan fisik}

Setiap jenis persediaan memiliki karakteristik tersendiri dan cara pengeluaran yang berbeda. (Assauri,2010:171) jenis-jenis persediaan fisik dapat dibedakan menjadi:

a. Persediaan Bahan Mentah (Raw Material Stock) :Yaitu persediaan dari barang-barang berwujud yang digunakan dalam proses produksi, barang yang dapat diperoleh dari sumber-sumber alam ataupun dibeli dari supplier atau perusahaan yang menghasilkan bahan baku bagi perusahaan atau pabrik yang menggunakannya. Bahan baku diperlukan oleh pabrik untuk diolah yang setelah melalui beberapa proses diharapkan menjadi barang jadi (finished goods).

b. Persediaan Bagian Produk atau Parts yang Dibeli (Purchased Parts/Components Stock) Yaitu persediaan barang-barang yang terdiri dari parts yang diterima dari perusahaan lain, yang dapat secara langsung diassembling dengan parts lain, tanpa melalui proses produksi sebelumnya. Persediaan Bahan-bahan atau barang- barang Perlengkapan (Supplier Stock) Yaitu persediaan barang-barang atau bahanbahan yang diperlukan dalam proses produksi untuk membantu berhasilnya produksi atau yang dipergunakannya dalam bekerjanya suatu perusahaan, tetapi tidak merupakan bagian atau komponen dari barang jadi.

c. Pesediaan Barang Setengah Jadi atau Barang Dalam Proses (Work in Process/Progress Work) Yaitu persediaan barang-barang yang keluar dari tiap-tiap bagian dalam satu pabrik atau bahan-bahan yang telah diolah menjadi suatu bentuk, tetapi lebih perlu diproses kembali untuk kemudian menjadi barang jadi. Tetapi mungkin saja barang setengah jadi suatu pabrik, merupakan bahan baku bagi perusahaan lainnya yang akan memprosesnya menjadi barang jadi. Jadi pengertian dari barang setengah jadi atau barang dalam proses adalah merupakan barang-barang yang belum berupa barang jadi. Akan tetapi masih merupakan proses lebih lanjut lagi di pabrik itu sehingga menjadi barang jadi yang sudah siap untuk dijual kepada pelanggan atau konsumen.

d. Persediaan Barang Jadi (Finished Goods Stock) Yaitu persediaan barang-barang yang telah selesai diproses atau diolah dalam pabrik dan siap untuk dijual kepada pelanggan atau perusahaan lain. Jadi barang jadi ini adalah merupakan produk selesai dan telah siap untuk dijual.

\section{Konsep Produksi}

Definisi Produksi Menurut Fuad (2010:142) pengertian produksi sebagai berikut:

"Suatu kegiatan atau proses yang mentransformasikan masukan (input) menjadi keluaran (output).' Menurut Alam (2010:52) "Kegiatan menambah faedah (atau kegunaan) suatu benda atau menciptakaan benda baru sehingga lebih bermanfaat dalam memenuhi kebutuhan. 'Berdasarkan beberapa pendapat yang dikemukakan diatas dapat ditarik kesimpulan bahwa "sebagai usaha untuk menciptakan atau menambah fedah ekonomi 
suatu benda dengan tujuan untuk memenuhi kebutuhan manusia.",

\section{Fungsi Produksi}

Fungsi produksi terkait dengan pertanggungjawaban dalam pengolahan dan pengubahan masukan (input) menjadi keluaran (output) berupa barang atau jasa yang akan memberikan pendapatan bagi perusahaan. Berikut 4 fungsi dalam produksi (Fuad,2010:146):

\section{Proses Pengolahan}

Merupakan metode atau teknik yang di gunakan untuk pengolahan masukan.

2. Jasa-jasa Penunjang

Merupakan sarana berupa pengorganisasian yang perlu untuk penetapan teknik dan metode yang akan dijalankan, sehingga proses pengolahan dapat dilaksanakan secara efektif dan efisien.

3. Perencanaan

Merupakan penetapan keterkaitan dan pengorganisasian dari kegiatan produksi dan operasi yang akan dilakukan dalam suatu dasar waktu atau periode tertentu.

4. Pengendalian atau Pengawasan

Merupakan fungsi untuk menjamin terlaksananya kegiatan yang sesuai rencana, sehingga maksud dan tujuan penggunaan dan pengolahan masukan dapat dilaksanakan.

\section{a. Rancangan Use Case Diagram}

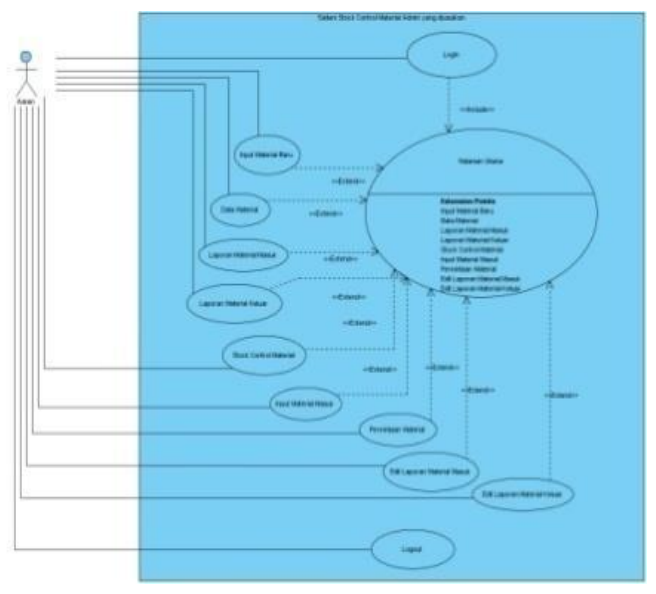

b. Rancangan Activity Diagram Admin Gudang

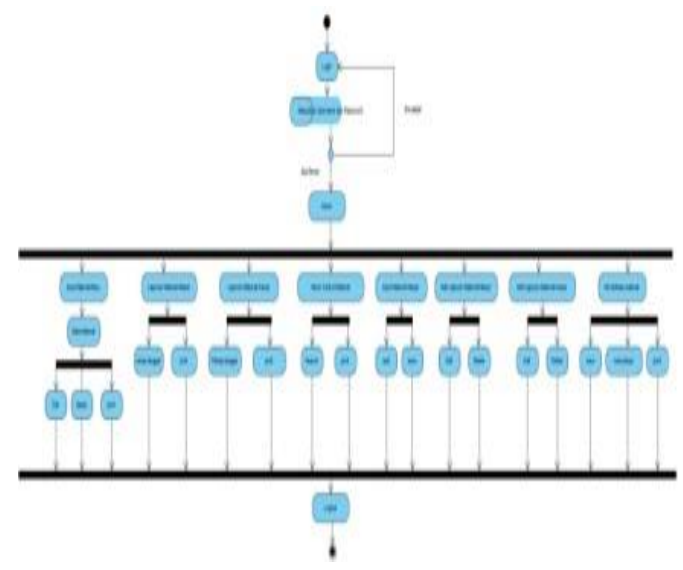

C. Rancangan Sequence Diagram
Admin Gudang

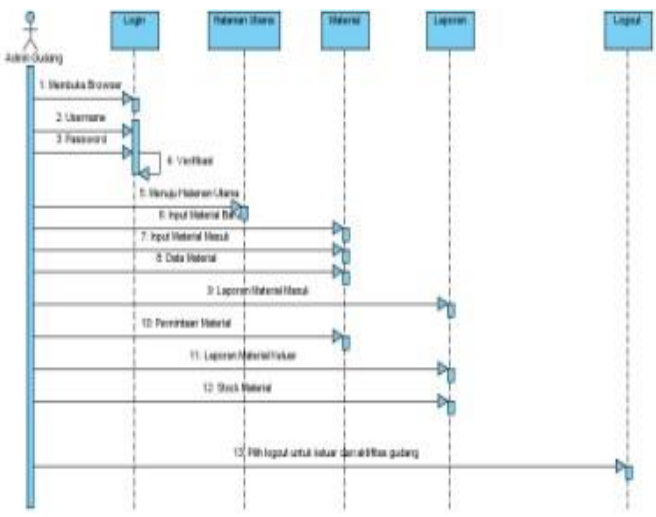

\section{Literature Review}

1. Penelitian oleh Widi Nugroho (2007), dengan judul "Perancangan Sistem Informasi Persedian Spare Parts Warehouse Engineering Pada PT. KMK Global Sports". Penelitian ini mambahas mengenai proses persediaan barang yang masih berjalan menggunkan sistem semi komputer, tetapi dalam penyimapanan data masih belum tersetruktur karena itu masih terjadi kesalahan dalam penginputan data karen dibutuhkan ketelitian yang tinggi sehingga meminimalkan kesalahan. Pada penelitian tersebut, penulis megusulkan sistem informasi dengan menggunakan aplikasi 
Visual Basic 6 dan Microsoft SQL server 2000."

2. Penelitian oleh Leonardi Winarsih (2009) dengan judul "Aplikasi Persediaan Barang Dagang Menggunakan Visual Basic 6.0". tujuan dari penelitian ini adalah merancang aplikasi persediaan barang dagang. Aplikasi dirancang menggunakan Visual Basic. Sistem persediaan barang menyimpan banyak data. Data dalam sistem ini dikelola menggunakan basis data, yang dirancang menggunakan konsep diagram entitas dan normalisasi. Tabel yang dihasilkan basis data adalah supplier, jenis barang, beli, jual, dan customer. Menggunakan aplikasi bagian persediaan dapat mengelola persediaan mencetak laporan secara langsung.

3. FAKULTAS TEKNOLOGI INDUSTRI INSTITUT SAINS \& TEKNOLOGI AKPRIND YOGYAKARTA yang dilakukan oleh Askin Setia Rinaldy (2009) dengan judul "SISTEM CLIENT/SERVER PENGOLAHAN DATA PERIPHERAL KOMPUTER DI TOKO MATRIX COMP YOGYAKARTA". Tujuan dari penelitian tersebut adalah merancang aplikasi persediaan barang dagangan. Aplikasi dirancang menggunkan visual basic. Sistem persediaan barang menyimpan banyak data. Data dalam sistem ini dikelola menggunakan basis data secara client/server, yang dirancang menggunakan konsep diagram entitas dan normalisasi. Komunikasi antar unit (client/server), dimulai pada saat aplikasi berjalan atau dieksekusi. Pada saat unit client aktif, dan melakukan transaksi. Maka unit client akan mengirim perintah ke unit sever, dari server akan dikembalikan hasil yang unit client minta. Data yang diproses pada unit server adalah database keseluruhan sistem, sedang yang dikirim ke client hanya hasil atau data tunggal saja, bukan seluruh database.

4. Penelitian oleh STMIK AMIKOM YOGYAKARTA yang dilakukan oleh Anita Manik (2010) dengan judul "ANALISIS PERANCANGAN DAN IMPLEMENTASI SISTEM INFORMASI STOK BARANG
DEVISI PENJUALAN MORNING COFFE YOGYAKARTA". Tujuan dari penelitian ini adalah merancang aplikasi penjualan barang dagangan. Aplikasi dirancang menggunakan visual basic. Sistem penjualan menyimpan banyak data. Data dalam sistem ini dikelola dengan menggunkan basis data Ms. Acces 2003, yang dirancang menggunkan konsep diagram entitas dan normaslisasi.

5. Penelitian Jurnal Ilmiah di kampus Universitas Indonesia mengenai teknologi Series. MAKARA Seri Teknologi adalah jurnal ilmiah yang menyediakan artikel asli tentang pengetahuan dan informasi riset atau aplikasi riset dan pengembangan kontemporer terkait dengan isu-isu teknologi - Jurnal ini merupakan alat publikasi dan sebuah forum untuk berbagi produk penelitian dan perkembangan dibidang teknologi. Setiap artikel untuk jurnal ini harus dikirim ke kantor redaksi. Informasi lengkap tentang cara mengirim artikel dan panduan penulisan disediakan di setiap publikasi. Setiap artikel akan menjalani proses seleksi oleh para ahli terkait dan atau editor. Sejak tahun 2010 jurnal ini diterbitkan semianually ( Juni dan Desember ) . Publikasi artikel tidak akan dikenakan biaya . MAKARA Seri Teknologi adalah perluasan MAKARA Seri B : Ilmu Pengetahuan dan Teknologi Daerah sebagai pengembangan Universitas Indonesia MAKARA Jurnal Penelitian yang diterbitkan sejak Januari 1997.

\section{Implementasi}

Adapun perangkat keras (hardware) yang digunakan dalam pembuatan program aplikasi juga perangkat lunak (software) yang digunakan sebagai penunjang dari peralatan komputer yang akan digunakan sebagai penghubung dalam instruksi yang diinginkan agar komputer diusulkan dalam rancangan sistem ini adalah : 


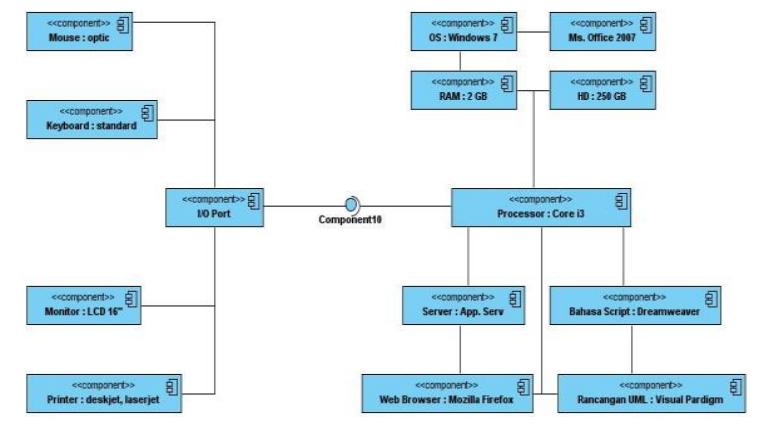

Gambar 1 Spesifikasi Hardware dan Software

a. Tampilan Login Admin Gudang.

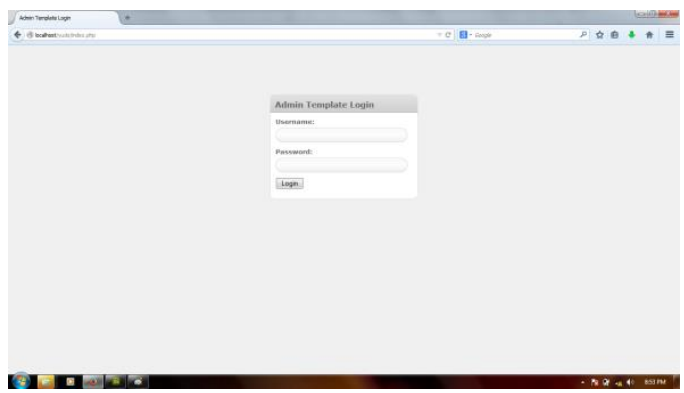

Gambar 2 Tampilan Login Admin.

b. Tampilan Login Produksi

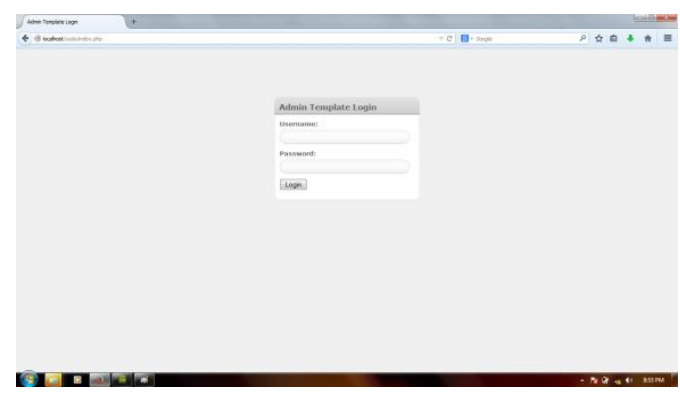

Gambar 3 Tampilan Login Produksi c. Tampilan Halaman Utama Admin Gudang

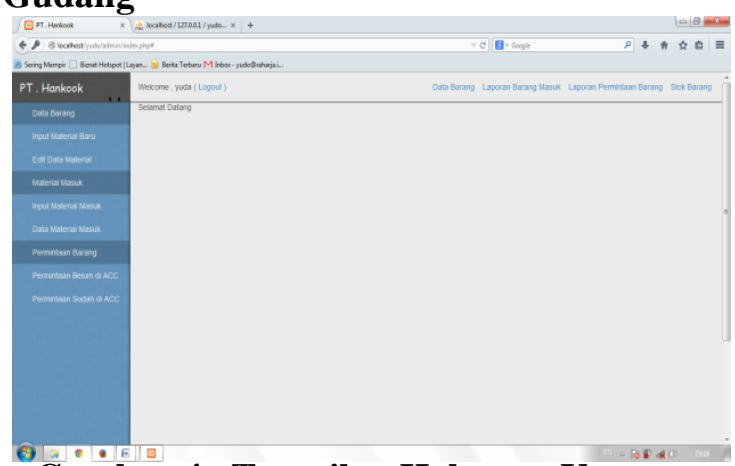

Gambar 4. Tampilan Halaman Utama Admin Gudang

d. Tampilan Halaman Utama Produksi

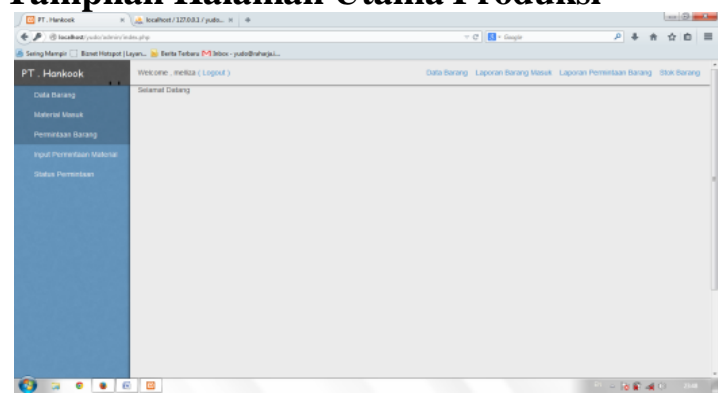

Gambar 5 Tampilan Halaman Utama Produksi

e. Tampilan Halaman Input Material Baru

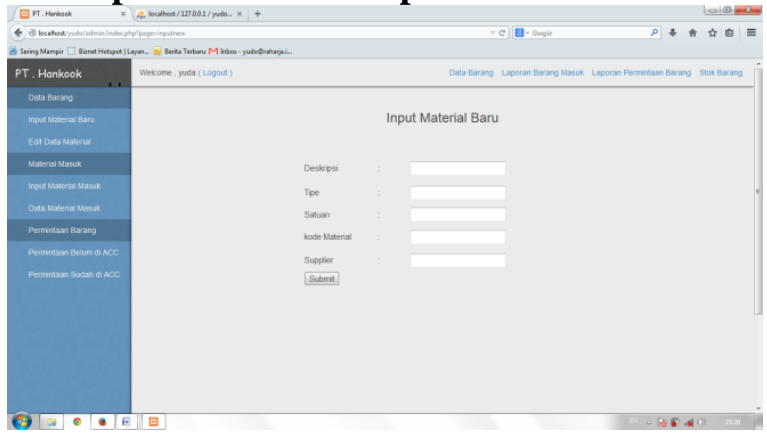

Gambar 6 Tampilan Halaman Input Material Baru 
f. Tampilan Halaman Input Material Masuk

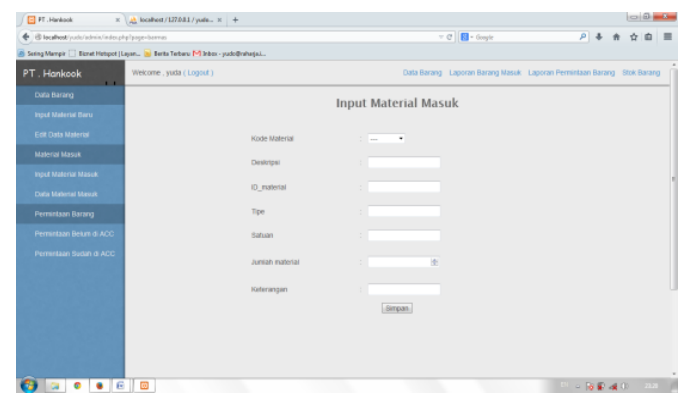

Gambar 7 Tampilan Halaman Inpu Material Masuk

g. Tampilan Halaman Nama User yang Melakukan Permintaan Material

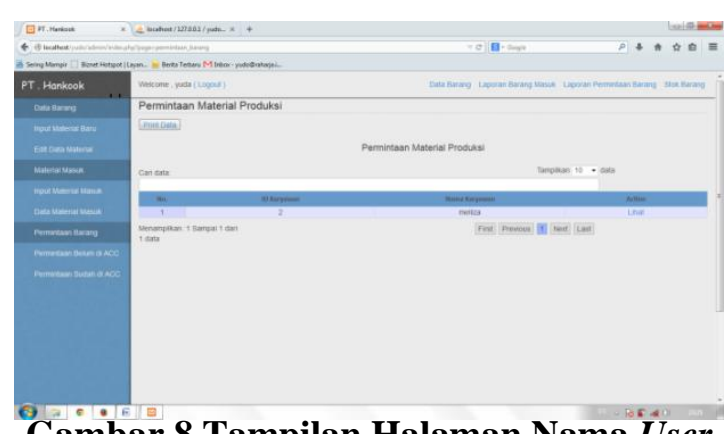

Gambar 8 Tampilan Halaman Nama User yang Melakukan Permintaan Material

h. Tampilan Halaman Permintaan Material dari Produksi

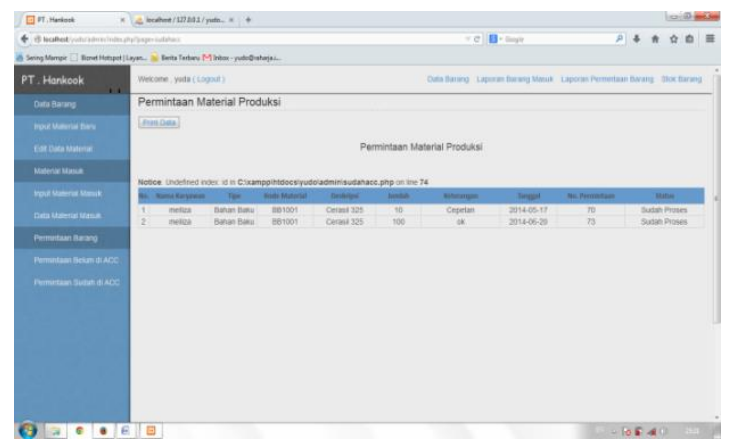

Gambar 9. ampilan Halaman Permintaan Material dari Produksi i. Tampilan Halaman Cara Edit Laporan Material Masuk

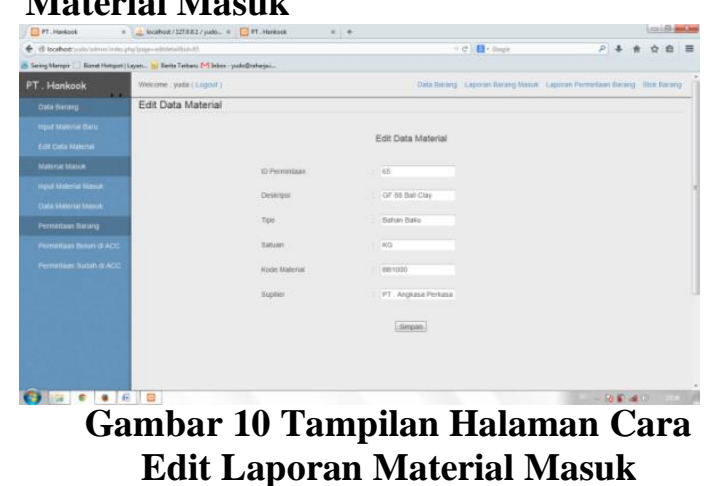

J. Tampilan Halaman Stock Control Material

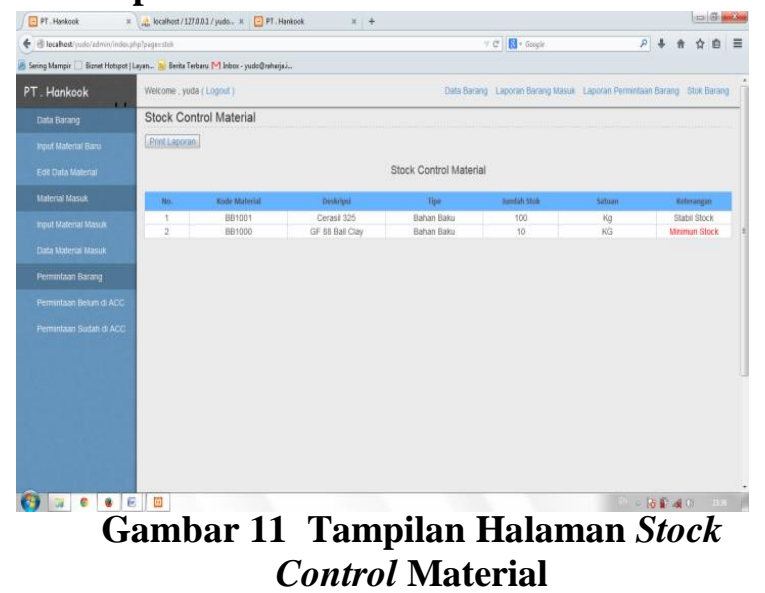

K. Tampilan Halaman Permintaan Material Produksi

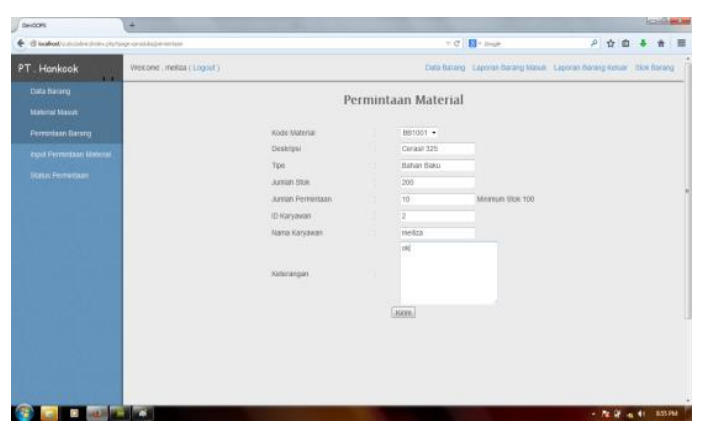

Gambar 12 Tampilan Halaman Permintaan Material Produksi 


\section{Kesimpulan}

Berdasarkan hasil penelitian dan observasi yang telah dilakukan pada sistem informasi persediaan barang pada PT. Hankook Ceramic Indonesia, maka penelitian dapat menarik Sistem informasi stock control material yang berjalan pada PT. Hankook Ceramic Indonesia masih menggunakan Ms. Excel dimulai dari penerimaan material dari supplier, pengambilan material ke produksi sampai menghasilkan laporan stock control material. Meskipun berjalan dengan baik namun menimbulkan keterlambatan dalam proses pengolahan data, menyebabkan informasi yang dihasilkan tidak akurat karena adanya perbedaan jumlah stock material antara data yang ada dengan fisiknya dan memerlukan waktu yang lama dalam penyajian laporannya. Sehingga untuk saat ini sistem yang berjalan masih belum memenuhi kebutuhan user. Sistem yang berjalan saat ini belum dapat memudahkan karyawan dalam memperoleh informasi hal ini disebabkan karena masih lamanya proses pencarian dan pembuatan laporannya, karena banyaknya dokumen yang diperlukan, sehingga proses pembuatan keputusan pun menjadi terhambat. Untuk merancang sistem informasi stock control material terkomputerisasi, yang dapat mempermudah stakeholder dalam menghasilkan laporan yang dibutuhkan untuk proses pengambilan keputusan oleh kepala gudang, dimulai dari penjabaran daftar kebutuhan yang dituangkan dalam elisitasi melalui 4 (empat) tahap, dengan menggunakan teknik MDI pada tahap ke dua, teknik TOE pada tahap ke tiga. Dilanjutkan dengan pembuatan diagram UML, yang terdiri dari lima buah diagram yaitu usecase diagram, sequence diagram, activity diagram, state chart diagram, dan class diagram sebagai awal rancangan sistem yang akan dibuat, selanjutnya dibuatlah programming dengan bahasa pemrograman PHP sesuai dengan desain prototype yang ada. App Serv sebagai pendukung aplikasi yang digunakan sebagai web server dan juga menggunakan MySQL sebagai database yang dibangun. Sebagai media tampilan menggunakan Dreamweaver sehingga dapat menyelesaikan permasalahan yang ada

\section{Daftar Pustaka}

[1] Menurut Gordon B. Davis dalam Sutarman, "Nilai Informasi dikatakan sempurna apabila perbedaan antara kebijakan optimal, tanpa informasi yang sempurna," Universitas Of Minnesota, 2012:14.

[2] Menurut Henderi, "langkah-langkah dalam penggunaan Unified Modeling Language (UML)," Universitas Gajah Mada, 2010:6

[3] Menurut Heriawati, "bahwa beberapa literature menyebutkan bahwa UnifiedModeling Language (UML) menyediakan Sembilan diagram, yang lain menyebutkan depalan karena ada beberapa diagram yang digabung," 2011:10

[4] Jogiyanto, "sistem dapat di klasifikasikan dari beberapa sudut pandang," Universitas Gajah Mada, 2011:8.

[5] John Burch dan Gary Grudnitski dalam Yustianti, "mengemukakan bahwa sistem informasi terdiri dari komponen-komponen yang disebutnya dengan istilah blok bangunan (building block)," California Democratic Politician and United States Congressman, 2012:14.

[6] McLeod dalam Yakub, "Informasi adalah data yang diolah menjadi bentuk yang lebih berguna bagi penerimanya," Yogyakarta: Graha Ilmu 2012:8.

[7] Mardi, "kualitas dari informasi (quality of information)," 2011:13

[8] Nugroho, Adi. Rekayasa Perangkat Lunak Menggunakan UML dan Java, Yogyakarta:Andi Offset.2010.

[9] Sutarman. 2012. "Buku Pengantar Teknologi Informasi". Jakarta: Bumi Aksara

[10] Sutabri, Tata. 2012. "Konsep Dasar Informasi". Yogyakarta: Andi

[11] Prabowo Pudjo Widodo. 2011. "Menggunakan UML". Informatika. Bandung.

[12] Tanti, Lili. 2009.Pengembangan Perangkat Ajar Berbantuan Komputer Untuk Mempelajari Tata Bahasainggris. Jurnal CCIT Vol. 3 No.2-Januari 2009: Tangerang.

[13] Maimunah 2012, Media Company Profile Sebagai Sarana Penunjang Informasi dan 
Promosi. Jurnal CCIT Vol.5 No.3- Mei 2012.

Tangerang:Perguruan Tinggi Raharja

[14] (Stephens dan Plew, 2013:337). "Database adalah kumpulan datanya, sedangkan program pengelolaannya berdiri sendiri dalam satu paket program yang komersial untuk membaca data, menghapus data dan melaporkan data dalam database".

[15] Ali (2010:3), menyatakan bahwa "Dreamweaver CS3 adalah sebuah HTML editor professional untuk mendesain web secara visual dan mengelola situs atau halaman web."

[16](Kusumawati,2010:178) pengertian produksi sebagai berikut: "Barang yang di beli/diproduksi/dimiliki perusahaan yang akan di jual kembali sebagai aktivitas atau kegiatan normal perusahaan. ",

[17] (Waluyo,2011:66) Barang jadi yang telah diproduksi atau barang dalam penyelesaian, termasuk bahan serta perlengkapan yang akan digunakan dalam proses produksi.

[18] Setiap jenis persediaan memiliki karakteristik tersendiri dan cara pengeluaran yang berbeda. (Assauri,2010:171) jenis-jenis persediaan fisik

[19] Menurut Fuad (2010:142) pengertian produksi, "Suatu kegiatan atau proses yang mentransformasikan masukan (input) menjadi keluaran (output)."

[20] Menurut Alam (2010:52) "Kegiatan menambah faedah (atau kegunaan) suatu benda atau menciptakaan benda baru sehingga lebih bermanfaat dalam memenuhi kebutuhan.',

[21]Menurut Jurnal CCIT Widayat Nurcahyo $(20010 ; 1)$ "Produksi adalah inti kegiatan maufaktur dengan menggunakan kriteria kehilangan penjualan dan keterlambatan produksi,kemudian memberikan alternatif" 